\title{
Involvement of calreticulin in cell proliferation, invasion and differentiation in diallyl disulfide-treated HL-60 cells
}

\author{
LAN YI ${ }^{1-3}$, JIAN SHAN $^{2}$, XIN CHEN $^{2}$, GUOQING LI ${ }^{1,3}$, LINWEI LI $^{1}$, HUI TAN $^{2}$ and QI SU $^{2}$ \\ ${ }^{1}$ College of Pharmacy and Biological Sciences; ${ }^{2}$ Cancer Research Institute; \\ ${ }^{3}$ Hunan Province Cooperative Innovation Center for Molecular Target New Drug Study, \\ University of South China, Hengyang, Hunan 421001, P.R. China
}

Received May 10, 2015; Accepted June 16, 2016

DOI: $10.3892 / 01.2016 .4850$

\begin{abstract}
Diallyl disulfide (DADS) has shown potential as a therapeutic agent in various cancers. Previously, calreticulin (CRT) was found to be downregulated in differentiated HL-60 cells treated with DADS. The present study investigated the role of CRT proteins in DADS-induced proliferation, invasion and differentiation in HL-60 cells. The present study demonstrated that DADS treatment significantly changed the morphology of HL-60 cells and caused the significant time-dependent downregulation of CRT. Small interfering RNA (siRNA)-mediated knockdown of CRT expression significantly inhibited proliferation, decreased invasion ability, increased the expression of cluster of differentiation (CD)11b and reduced the expression of CD33 in DADS-treated HL-60 cells. DADS also significantly affected cell proliferation, invasion and differentiation in CRT-overexpressed HL-60 cells. Nitroblue tetrazolium (NBT) reduction assays showed decreased NBT reduction activity in the CRT overexpression group and increased NBT reduction in the CRT siRNA group. Following treatment with DADS, the NBT reduction abilities in all groups were increased. In conclusion, the present study clearly demonstrates the downregulation of CRT during DADS-induced differentiation in HL-60 cells and indicates that CRT is involved in cell proliferation, invasion and differentiation in DADS-treated HL-60 cells.
\end{abstract}

\section{Introduction}

Acute myeloid leukemia (AML) is a genetically heterogeneous clonal disorder caused by the build up of somatic mutations in hematopoietic progenitor cells, which affects the regulation of self-renewal, survival, proliferation and differentiation (1).

Correspondence to: Professor Qi Su, Cancer Research Institute, University of South China, 28 Changshengxi Road, Hengyang, Hunan 421001, P.R. China

E-mail: suqi1945@163.com

Key words: diallyl disulfide, proliferation, invasion, differentiation, HL-60 cells, calreticulin
The induction of differentiation is a desired consequence of chemopreventive and therapeutic agents, as it often results in the elimination of premalignant or malignant cells (2). Numerous studies focus on selectively killing tumor cells through differentiation induction (3). Therefore, the development of novel differentiation-inducing drugs for blocking AML is of clinical significance.

For the past 30 years, studies have explored the use of diallyl disulfide (DADS), the main active component of the cancer-fighting allyl sulfides found in garlic, as it has been shown to reduce the initiation of carcinogen-induced cancers and inhibit the proliferation of various types of cancer cells (4). The actions of DADS include the regulation of cell cycle arrest, induction of apoptosis and cell differentiation, and inhibition of cell invasion (5-7). Previous studies at the Cancer Research Institute, University of South China (Hengyang, China) confirmed that DADS can inhibit the proliferation of human leukemia cells in vivo in a dose-dependent manner $(8,9)$. DADS exhibits a dual effect: A medium dose $(>1.25 \mathrm{mg} / \mathrm{l})$ can induce apoptosis in human leukemia cells $(8,9)$, and a small dose $(<1.25 \mathrm{mg} / \mathrm{l})$ can induce human leukemia cell differentiation (2). The mechanisms of inducing differentiation involve: $\mathrm{G}_{2} / \mathrm{M}$-phase cell cycle arrest; histone acetylation; the regulation of regulatory gene expression, including signal transducer and activator of transcription 3, v-myc avian myelocytomatosis viral oncogene homolog, Fos proto-oncogene and Jun proto-oncogene regulation; and the upregulation of cyclin-dependent kinase inhibitor 1 expression (10-12). Proteomic analysis was also used to explore differentially expressed proteins in DADS-induced differentiation in human leukemiaHL-60 cells (13). The results showed decreased expression of calreticulin (CRT), an endoplasmic reticulum-resident protein, in differentiated HL-60 cells induced by DADS (13), suggesting that CRT is involved in DADS-mediated induction of differentiation in HL-60 cells. Although the role of DADS as an antitumor agent has been established, its exact cytotoxic mechanism in differentiation is not entirely clear.

CRT, a multi-process calcium-buffering chaperone of the endoplasmic reticulum, is essential for numerous cellular functions, including lectin-like chaperoning, $\mathrm{Ca}^{2+}$ storage and signaling, the regulation of gene expression, cell adhesion, wound healing, cancer and autoimmunity (14). Recently, numerous studies have shown that CRT is important in tumorigenesis and 
prognosis $(15,16)$. The increased expression of CRT was indicated in the urine samples of patients with bladder cancer, indicating CRT as a biomarker in bladder cancer (17). In gastric cancer, positive immunohistochemical staining of CRT was correlated with high microvessel density, serosal and perineural invasion, lymph node metastasis and poor patient survival (18). However, in neuroblastoma, which is the most common malignancy in infants, positive immunohistochemical staining for CRT was associated with a better prognosis and patient survival (19). CRT was also differentially expressed in colorectal cancer (20). CRT-overexpressing gastric cancer cells demonstrate increased proliferation rates, while CRT-knockdown gastric cancer cell lines demonstrated decreased proliferation rates (20). In addition, CRT-overexpressing cells showed greater wound healing and migration rates compared with CRT-knockdown cells (21). In a recent preliminary study of 33 breast cancer patients, Kabbage et al (22) observed a potential association between CRT overexpression and axillary lymph node metastasis in breast cancer patients.

Certain studies have indicated that CRT is upregulated in all AML subtypes in the French-American-British classification of leukemia cells $(23,24)$. In addition, the expression of CRT was significantly reduced during certain drug-induced leukemia cell differentiation (25).

In the present study, CRT was hypothesized to be an important factor in DADS-induced proliferation, migration and differentiation in human leukemia HL-60 cells. The present study examined the role of CRT on migration and differentiation in human leukemia HL-60 cells treated with DADS. These results may lead to a better understanding of the antitumor molecular mechanisms of DADS and provide essential knowledge for the development of differentiation inducers to treat leukemia.

\section{Materials and methods}

Materials and reagents. Fluka Chemika Company DADS was purchased from Sigma-Aldrich (Buchs, Switzerland). The Total RNA Kit II extraction kit was purchased from Omega Bio-Tek, Inc. (Norcross, GA, USA). A High Capacity cDNA Reverse Transcription kit was purchased from Promega Corporation (Madison, WI, USA). The Bestar ${ }^{\mathrm{TM}}$ qPCR RT Kit (\#DBI-2220) and Bestar ${ }^{\mathrm{TM}}$ SybrGreen qPCR Mastermix (\#DBI-2043) were purchased from DBI Bioscience (Ludwigshafen, Germany). The CRT (mouse monoclonal; \#ab22683; dilution, 1:500), GAPDH (mouse monoclonal; \#ab8245; dilution, 1:500), cluster of differentiation (CD)11b (rabbit monoclonal; \#ab52478; dilution, 1:200) and CD33 (mouse monoclonal; \#ab119860; dilution, 1:200) primary antibodies, and the horseradish peroxidase-conjugated secondary antibodies [goat anti-mouse IgG H\&L (\#ab6789; dilution, 1:1,000) and goat anti-rabbit IgG H\&L (\#ab6721; dilution, 1:1,000)] were purchased from Abcam (Cambridge, UK). Small interfering RNA (siRNA) transfection reagent, siRNA transfection medium, CRT siRNA and a O-GlcNAc Western Blot Detection Kit were purchased from Santa Cruz Biotechnology (Dallas, TX, USA). Nitroblue tetrazolium (NBT) was purchased from Sigma-Aldrich (St. Louis, MO, USA). The Invitrogen plasmids (pcDNA3.1-12GS0643-IG-3, KL121217003) and vector (pcDNA3.1) were obtained from Thermo Fisher Scientific, Inc. (Waltham, MA, USA).
Cell culture. Human AML HL-60 cells, obtained from Central South University (Hengyang, China), were incubated in RPMI-1640 culture medium (Hyclone; GE Healthcare Life Sciences, Logan, UT, USA) containing $10 \%$ calf serum (Gibco; Thermo Fisher Scientific, Inc.) at $37^{\circ} \mathrm{C}$, at saturated humidity and $5 \% \mathrm{CO}_{2}$. Cell cultures were replaced with fresh medium every 2-3 days. Cells in logarithmic growing phase were used for experiments. DADS was diluted to $1.25 \mathrm{mg} / \mathrm{lin}$ culture medium.

Wright-Giemsa staining. Cells were collected, smeared on a slide and air-dried. Subsequently, 2-3 drops of Wright-Giemsa dye solution were added to the cells, and after $1 \mathrm{~min}$, the slide was rinsed with distilled water. The sample was dried and observed under a microscope.

Reverse transcription-quantitative polymerase chain reaction (RT-qPCR). Expression levels of the CRT gene in HL-60 cells were measured by SYBR Green RT-qPCR. $\beta$-actin was used as an internal control. All primer sequences were designed by Premier 5.0 software (Premier Biosoft International, Palo Alto, CA, USA) and synthesized by Takara Bio Inc. (Otsu, Japan). The primer sequences were as follows: $\beta$-actin sense, 5 '-GGA CCTGACTGACTACCTC-3' and antisense, 5'-TAGTCGTTC GTCCTCATAC-3'; and CRT sense, 5'-GGAAGATGAGGA GGAAGATGTC-3' and antisense, 5'-CAGGAAGGAGAG CAGATGAAAT-3'. Total cell RNA was extracted according to the instructions of the Total RNA Kit II (Omega Bio-Tek, Inc.), and the RNA purity and concentration were measured using a NanoDrop ${ }^{\circledR}$ ND-1000 (Thermo Fisher Scientitic, Inc.). Total RNA was subjected to RT by first heating $10 \mu \mathrm{l}$ of the annealing mixture, which contained $2 \mu \mathrm{g}$ total RNA and $1 \mu \mathrm{l}$ $0.5 \mu \mathrm{g} / \mu \mathrm{l}$ oligo $(\mathrm{dT})_{18}$, to $70^{\circ} \mathrm{C}$ for $3 \mathrm{~min}$. After cooling to $37^{\circ} \mathrm{C}$ for $10 \mathrm{~min}, 2 \mu 110 \mathrm{X}$ RT reaction buffer, $4 \mu 12.5 \mathrm{mM}$ dNTP mixture, $1 \mu \mathrm{l}$ RNase inhibitor and 200 units of moloney murine leukemia virus reverse transcriptase were added. In a PCR machine (Applied Biosystems; Thermo Fisher Scientific, Inc.), the mixture was first incubated at $37^{\circ} \mathrm{C}$ for $1 \mathrm{~h}$, then heated to $95^{\circ} \mathrm{C}$ for $5 \mathrm{~min}$ and cooled on ice. For qPCR, a $25-\mu 1$ reaction mixture, consisting of $1 \mu \mathrm{l}$ cDNA, $1 \mu \mathrm{l}$ Primer1, $1 \mu \mathrm{l}$ Primer2, 2x1 unit Taq Master Mix, $2.5 \mu 12.5$ mM dNTPs, $2.5 \mu \mathrm{l}$ 10X PCR buffer, $1.5 \mu \mathrm{lgCl}_{2}$ and 10,000-fold diluted SYBR Green, was used. All PCR reactions were performed at $95^{\circ} \mathrm{C}$ for $5 \mathrm{~min}$, followed by 40 cycles of $95^{\circ} \mathrm{C}$ for $10 \mathrm{sec}, 59^{\circ} \mathrm{C}$ for $15 \mathrm{sec}$, and $72^{\circ} \mathrm{C}$ for $20 \mathrm{sec}$. In order to establish the melting curve of PCR products obtained from the reaction, the samples were then heated between 72 and $99^{\circ} \mathrm{C}$, rising $1^{\circ} \mathrm{C}$ every $5 \mathrm{sec}$. The results were quantified by dissociation and amplification curves (26).

Fast-forward transfection cell transfection. Experimental plasmid (pcDNA3.1-12GS0643-IG-3), negative plasmid (pcDNA3.1-neg-IRES2-EGFP) and vectors (pcDNA3.1), $0.4 \mu \mathrm{g}$ each, were dissolved in Tris-ethylenediaminetetraacetic acid (TE) buffer ( $\mathrm{pH} 7-8$; minimum DNA concentration, $0.1 \mu \mathrm{g} / \mu \mathrm{l}$ ) with RPMI-1640 without serum, proteins or antibiotics to a total volume of $60 \mu \mathrm{l}$. Attractene transfection reagent (Qiagen, Inc., Valencia, CA, USA) (1.5 $\mu \mathrm{l})$ was added to the DNA and mixed by pipetting or vortexing, and if necessary, the sample was centrifuged for a few seconds to remove any liquid from 
the top of the tube. The samples were incubated for 10-15 min at room temperature to allow transfection complex formation, and then added to $500 \mu \mathrm{l}$ of freshly harvested cell suspension (to a final cell density of $0.4-1.6 \times 10^{5}$ cells in $500 \mu \mathrm{l}$ ), which was added to a well of a 24-well plate. Cells were incubated with the transfection complexes under normal growth conditions and assayed $24 \mathrm{~h}$ after the fast-forward transfection.

RNA interference. Cells were collected through centrifugation and the concentration was adjusted to $1-2 \times 10^{6}$ cells $/ \mathrm{ml}$. The cells were then washed once with $2 \mathrm{ml}$ siRNA transfection medium. Two various preparations were used: Solution A, consisting of $6 \mu \mathrm{l}$ CRT siRNA duplex in $100 \mu \mathrm{l}$ siRNA transfection medium, and solution $\mathrm{B}$, including $6 \mu \mathrm{l}$ siRNA transfection reagent in $100 \mu l$ siRNA transfection medium. Solution A was then directly added to solution B using a pipette, and the solutions were mixed gently and incubated for $30 \mathrm{~min}$ at room temperature. siRNA transfection medium $(0.8 \mathrm{ml})$ was added to each tube containing the siRNA transfection reagent mixture, and the mixture was overlaid onto cells. Cells were incubated for $5-7 \mathrm{~h}$ at $37^{\circ} \mathrm{C}$ in a $\mathrm{CO}_{2}$ incubator, and then $1 \mathrm{ml}$ of normal growth medium containing two times the normal serum amount ( $8 \%$ calf serum) was directly added without removing the transfection mixture. Cells were incubated for an additional 18-24 h, after which the medium was removed and replaced with fresh normal growth medium. At 24-72 h, cells were harvested for analysis.

Western blot analysis. Total cell proteins from the different groups were harvested (untreated HL-60 cells were used as the normal control), and $25 \mu \mathrm{g}$ of each sample was mixed with $5 \mathrm{X}$ sodium dodecyl sulfate (SDS) loading buffer at 5:1 ratio, denatured by heating, and separated by $10 \%$ SDS-polyacrylamide gel electrophoresis. Samples were transferred to a nitrocellulose membrane, and membranes were blocked with Tris-buffered saline and Tween 20 (TBST) containing $5 \%$ non-fat milk for $2 \mathrm{~h}$. The membrane was washed with TBST three times, and incubated with the CRT, CD11b, CD33 or GAPDH (internal control) primary antibodies for $2 \mathrm{~h}$ at $37^{\circ} \mathrm{C}$, followed by three washes with TBST for $15 \mathrm{~min}$ each. The membranes were incubated with the corresponding secondary antibody for $1 \mathrm{~h}$, washed with TBST three times for 10 min each, and finally developed using BeyoECL Plus (Beyotime Biotechnology, Turku, Finland).

Invasion assay. Transwell inserts (pore diameter, $8 \mu \mathrm{m}$; diameter, $6.3 \mathrm{~mm}$ ) were inserted in the chamber of a 24-well transwell plate. Serum-free RPMI-1640 with BD Matrigel (5 mg/ml; dilution, 8:1; BD Biosciences, Franklin Lakes, NJ, USA) was added into the bottom of the Transwell chamber and plates were incubated at $37^{\circ} \mathrm{C}$ overnight. Cells $\left(1 \times 10^{6}\right.$ cells $\left./ \mathrm{ml}\right)$ of the different groups (with untreated HL-60 cells used as the normal control) were added into the upper chamber, and RPMI-1640 medium containing serum was added into the lower chamber. The plates were incubated for $48 \mathrm{~h}$, the supernatant was removed, and then the plates were washed with phosphate-buffered saline (PBS). Samples were fixed with $10 \%$ formalin for 20-30 min, stained with hematoxylin for 10-20 min and air-dried. The invading cells were counted using an inverted microscope. 3-(4,5-dimethylthiazol-2-yl)-2,5-diphenyl-tetrazolium bromide (MTT) assay. Cell viability was determined using a conventional MTT reduction assay (27). HL-60 cells ( $1 \times 10^{4}$ cells/well) in 96 -well plates were treated with $1.25 \mathrm{mg} / \mathrm{l}$ DADS for $48 \mathrm{~h}$. Untreated HL-60 cells were used as the normal control. The medium was removed and $100 \mu \mathrm{l}$ of dimethyl sulfoxide was added to each well to dissolve the formazan dye crystals for $15 \mathrm{~min}$. The optical density was measured at an absorbance of $490 \mathrm{~nm}$ with a microplate reader.

Differentiation assay. NBT reduction was performed as previously described (28). Cells were incubated in 96-well culture plates and collected through centrifugation. Cells were the resuspended with $200 \mu \mathrm{l}$ NBT solution. Following $60 \mathrm{~min}$ of culture, centrifugation was performed, $200 \mu \mathrm{l}$ DMSO was added and the cells were oscillated for $20 \mathrm{~min}$. Absorbance was measured at $570 \mathrm{~nm}$.

Flow cytometry (FCM) analysis. To evaluate the effect of CRT siRNA transfection and CRT overexpression on HL-60 cells, CD11b and CD33 levels were evaluated. Cells from the different groups (with untreated HL-60 cells included as the normal control) were collected, centrifuged at $500 \mathrm{x}$ g for $5 \mathrm{~min}$, washed twice with PBS, and the cell concentration was adjusted to $1 \times 10^{6}$ cells $/ \mathrm{ml}$. Cells were then fixed with $70 \%$ ethanol. Prior to FCM analysis, the cells were washed twice again with PBS and $500 \mu 10.2 \%$ Triton-X 100 was added. The mixture was incubated on ice for $10 \mathrm{~min}$. After washing the samples twice again with PBS, $50 \mu 1$ primary antibody was added and cells were incubated on ice for 30-45 min. After washing with PBS, $50 \mu \mathrm{l}$ specific fluorescent secondary antibody was added, and cells were incubated on ice for $30 \mathrm{~min}$. Subsequent to washing with PBS, the cells were immediately measured by FCM (FlowJo version 9; FlowJo, LLC, Ashland, OR, USA).

Statistics. SPSS 12.0 statistical software (SPSS, Inc., Chicago, IL, USA) was used to analyze the results. Experimental data were presented as mean \pm standard deviation, and the differences between experimental and control groups were detected by the Student's $t$-test. $\mathrm{P}<0.05$ was considered to indicate a statistically significant difference.

\section{Results}

Calreticulin is downregulated during DADS-induced differentiation in HL-60 cells. As shown in Fig. 1A, the treatment of HL-60 cells with $1.25 \mathrm{mg} / 1$ DADS for $48 \mathrm{~h}$ induced cells to differentiate into granulocyte-like cells. The cytomorphoses of the DADS-treated cells were clearly varied from the controls. RT-PCR confirmed the significant downregulation of CRT messenger RNA (mRNA) levels in HL-60 cells following treatment with $1.25 \mathrm{mg} / 1$ DADS in a time-dependent manner, compared with untreated HL-60 cells ( $\mathrm{P}=0.042$; Fig. 1B). Western blot analysis was consistent with the RT-PCR results, showing a decrease in CRT protein levels in HL-60 cells treated with $1.25 \mathrm{mg} / \mathrm{l}$ DADS in a time-dependent manner ( $\mathrm{P}=0.021$; Fig. $1 \mathrm{C}$ and $\mathrm{D})$.

CRT affects proliferation of DADS-treated HL-60 cells. The present study then analyzed the functional role of CRT 
A
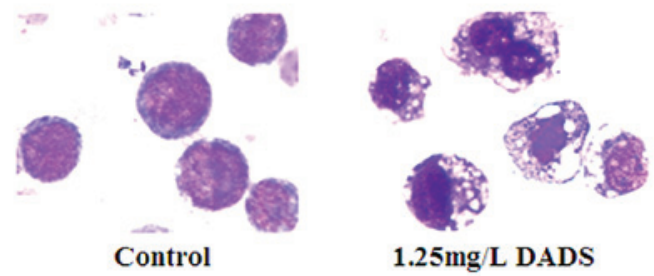

C

$1.25 \mathrm{mg} / \mathrm{L}$ DADS

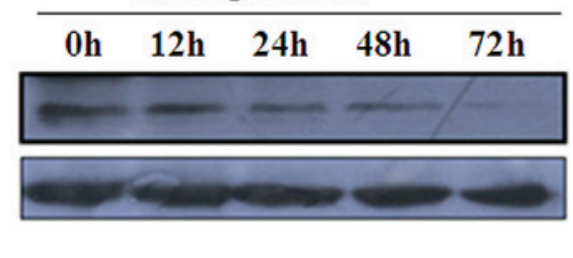

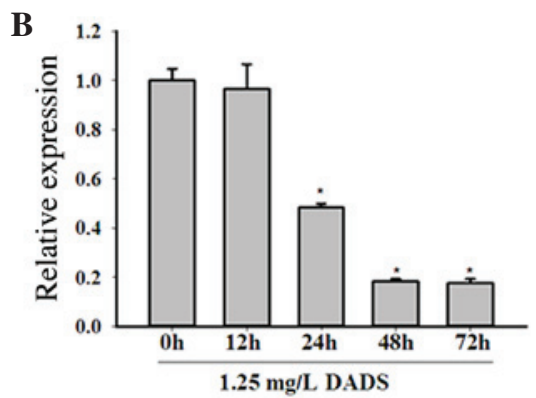

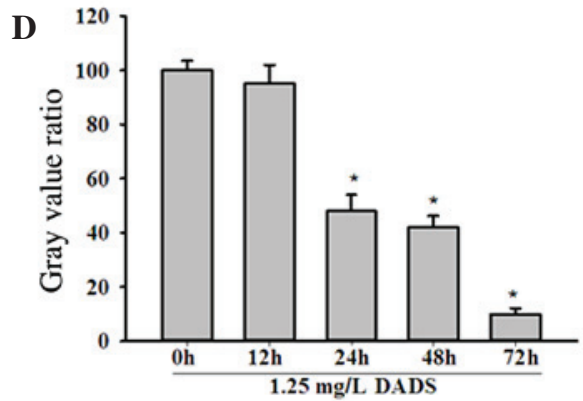

Figure 1. Downregulation of CRT during DADS-induced differentiation in HL-60 cells. (A) Morphological changes of HL-60 cells after 1.25 mg/l DADS treatment for $48 \mathrm{~h}$ (Wright-Giemsa staining; magnification, x100). (B) CRT messenger RNA levels in HL-60 cells were decreased by $1.25 \mathrm{mg} / 1$ DADS treatment at 24,48 and $72 \mathrm{~h}$, as determined by reverse transcription-quantitative polymerase chain reaction (relative to $\beta$-actin). " $\mathrm{P}<0.05$ vs. control cells. (C) Representative western blot analysis of CRT expression using GAPDH as the internal control. (D) Quantification of CRT expression in western blot analyses. Values are mean \pm standard deviation from three independent experiments. "P<0.05 vs. control cells. CRT, calreticulin; DADS, diallyl disulfide; GAPDH, glyceraldehyde 3-phosphate dehydrogenase.
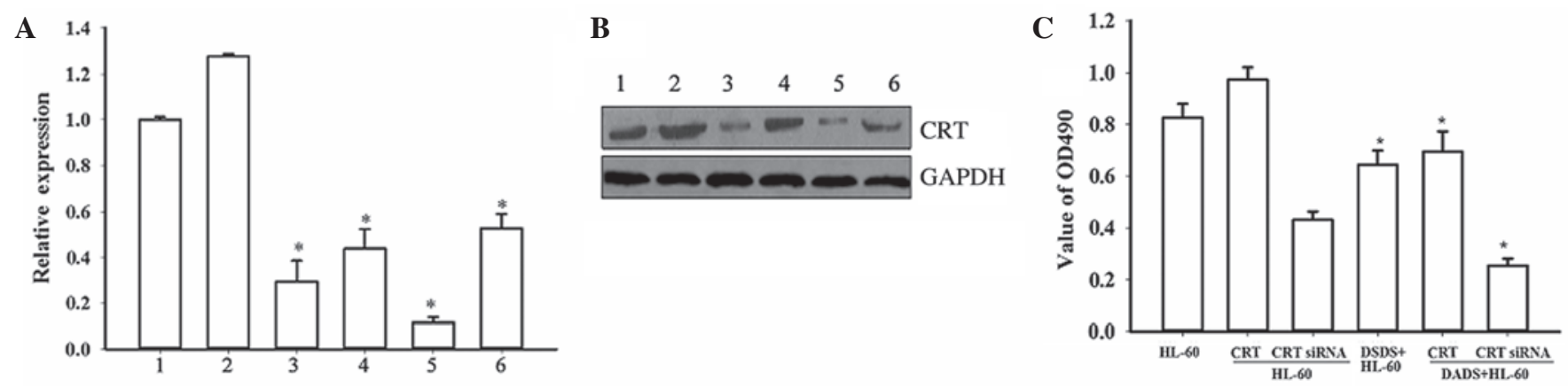

Figure 2. Effect of CRT overexpression and CRT downregulation on proliferation of HL-60 cells induced by DADS. Inhibition of CRT expression by siRNA and CRT overexpression by plasmid transfection in HL-60 cells were evaluated by (A) reverse transcription-polymerase chain reaction: 1, HL-60; 2, HL-60/CRT; 3, HL-60/CRT siRNA; 4, DADS+HL-60; 5, DADS+HL-60/CRT siRNA; 6, DADS+HL-60/CRT ("P<0.05 vs. control cells) and (B) western blot analysis: 1, HL-60; 2, HL-60/CRT; 3, HL-60/CRT siRNA; 4, DADS+HL-60; 5, DADS+HL-60/CRT siRNA; 6, DADS+HL-60/CRT. (C) 3-(4,5-dimethylthiazol-2-yl)-2,5-diphenyl-tetrazolium bromide analysis in CRT-overexpressing and CRT-downregulated HL-60 cells, with and without DADS treatment. ${ }^{\text {*P }}<0.05$ vs. control cells. CRT, calreticulin; DADS, diallyl disulfide; siRNA, small interfering RNA; GAPDH, glyceraldehyde 3-phosphate dehydrogenase.

in DADS-induced effects on HL-60 cells using CRT overexpression and CRT downregulation mediated by siRNA. The RT-PCR and western blot analyses confirmed that CRT knockdown by RNA interference was $70 \%$. In the DADS+siRNA-treated group, CRT expression was further inhibited $(\mathrm{P}=0.027)$. Notably, upon treatment of untransfected and CRT-overexpressing cells with $1.25 \mathrm{mg} \cdot \mathrm{l}^{-1}$ DADS for $48 \mathrm{~h}, \mathrm{CRT}$ levels were significantly reduced compared with the corresponding untreated cells $(\mathrm{P}=0.019)$, indicating that DADS could downregulate CRT expression in HL-60 cells (Fig. 2A and B).

MTT assays demonstrated that downregulation of CRT by siRNA resulted in decreased proliferation of HL-60 cells compared with the controls, while CRT overexpression increased cell proliferation (Fig. 2C). These results indicate that CRT has a function in HL-60 cell proliferation. Notably, following treatment with DADS for $48 \mathrm{~h}$, the proliferation rates of all cells were decreased compared with the corresponding untreated groups $(\mathrm{P}=0.038)$. Together, these data indicate that CRT is involved in cell proliferation in DADS-induced HL-60 cells.

CRT affects cell invasion in DADS-treated HL-60 cells. The present study next investigated the role of CRT in cell invasion induced by DADS treatment. Transwell Matrigel invasion assays showed that the number of HL-60 cells that penetrated through the Matrigel in the non-transfected group was $62 \pm 6.37$, compared with $83 \pm 11.39$ in the CRT overexpression group 

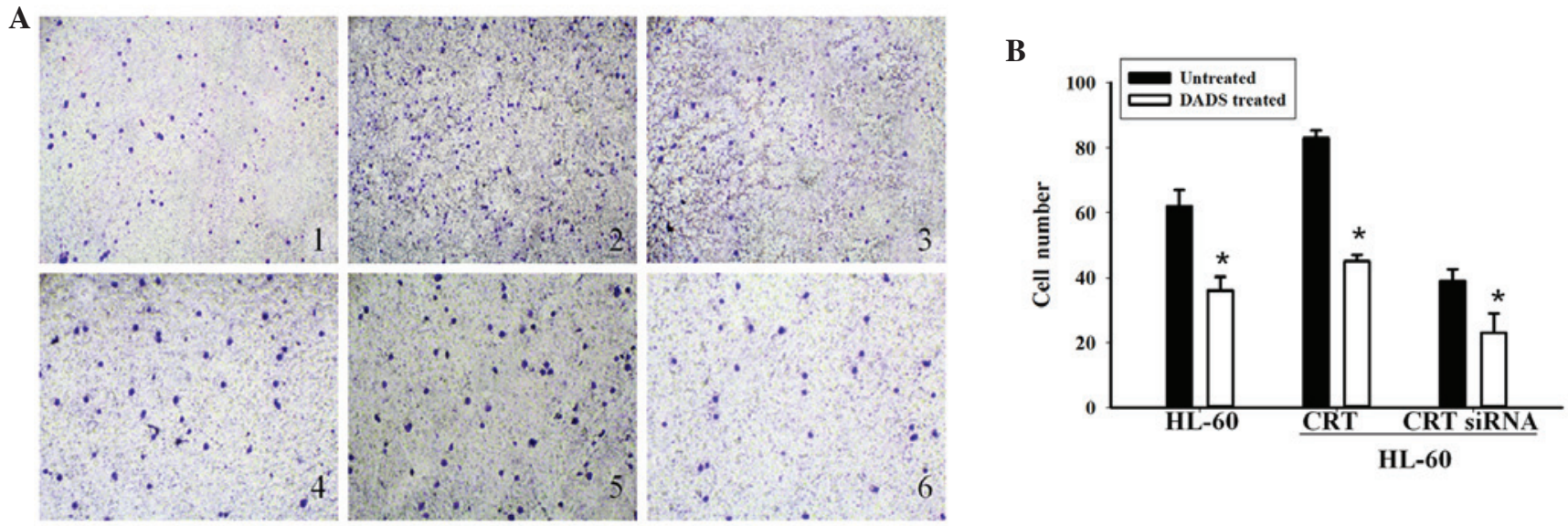

Figure 3. Role of CRT in cell invasion of HL-60 cells induced by DADS. (A) Representative experiment of Transwell invasion assays (magnification, x200): 1, HL-60 cells; 2, CRT-overexpressing HL-60 cells; 3, CRT-downregulated HL-60 cells; 4, DADS-treated HL-60 cells; 5, DADS-treated CRT-overexpressing HL-60 cells; 6, DADS-treated CRT-downregulated HL-60 cells. (B) Values are mean \pm standard from three independent experiments. "P<0.05 vs. control cells. CRT, calreticulin; DADS, diallyl disulfide.

A
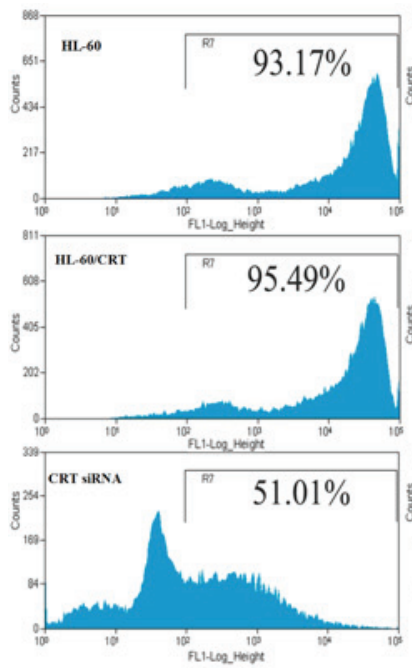
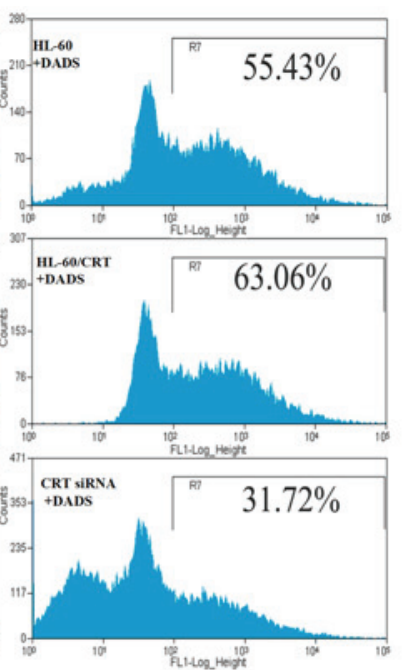

B
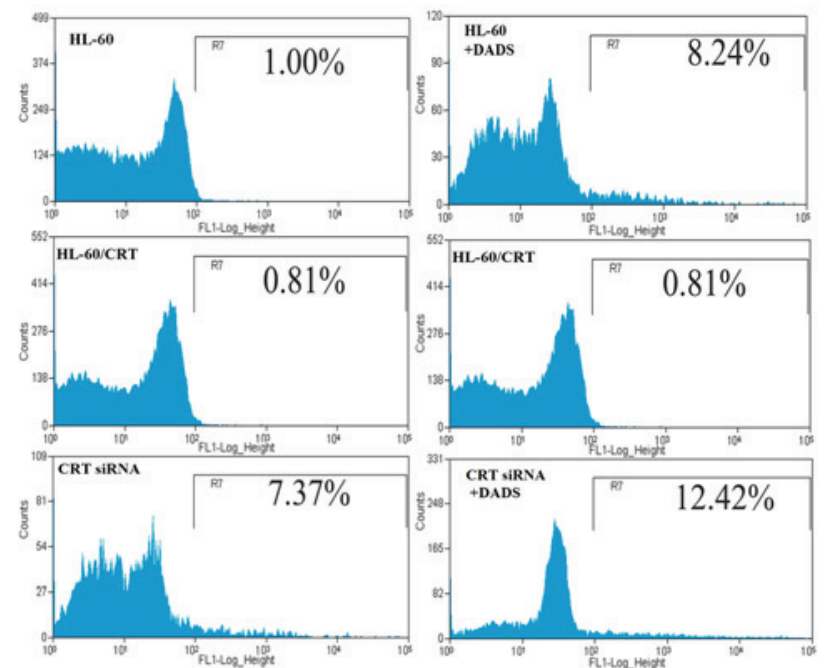

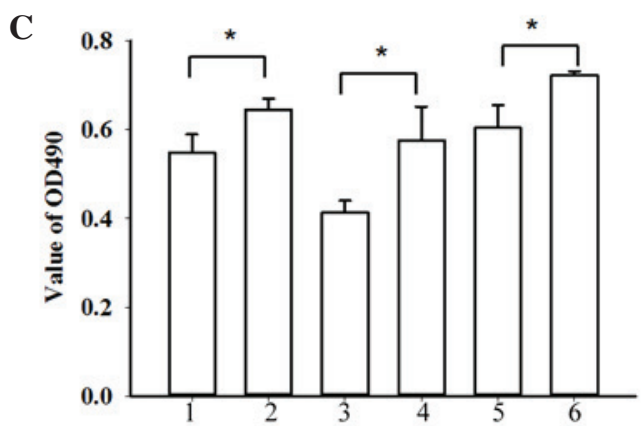

Figure 4. Role of CRT in cell differentiation of HL-60 cells induced by DADS. (A) Representative flow cytometry results showing CD33 expression. (B) Representative flow cytometry results showing CD11b expression. (C) Nitroblue tetrazolium reduction assays: 1, HL-60; 2, DADS+ HL-60; 3, HL-60/CRT; 4, DADS+HL-60/CRT; 5, HL-60/CRT siRNA; 6, DADS+HL-60/CRT siRNA. Data are the mean \pm standard deviation of three experiments. ${ }^{*}$ < $<0.05$ vs. control; Student's $t$-test. CRT, calreticulin; DADS, diallyl disulfide; CD33, cluster of differentiation 33; CD11b, cluster of differentiation 11b; OD, optical density.

and $39 \pm 2.43$ in the CRT siRNA group (Fig. 3A and B). These results indicate that CRT overexpression can increase the ability of invasion in HL-60 cells and CRT siRNA transfection can decrease the ability of invasion. Following treatment with DADS for $48 \mathrm{~h}$, the number of HL-60 cells that penetrated through the Matrigel was 36.2 \pm 7.59 in the non-transfected group, compared with $45.6 \pm 4.10$ and $23.45 \pm 3.86$ in the CRT overexpressing and downregulated groups, respectively. Cellular invasion in the DADS treated groups was decreased compared with the untreated groups $(\mathrm{P}=0.034)$. These results indicate that CRT is involved in cell invasion in DADS-induced HL-60 cells.

CRT affects cell differentiation in DADS-treated HL-60 cells. The present study finally investigated the role of CRT 
in cell differentiation induced by DADS treatment. As shown in Fig. 4A, FCM analysis showed that, compared with control cells, the expression of CD33 in the CRT siRNA group was markedly reduced ( 93.53 vs. $51.22 \%$, respectively), while the CRT-overexpressed groups showed slightly increased CD33 expression (95.76\%). Following treatment with DADS for $48 \mathrm{~h}$, the expression of CD33 was significantly decreased in non-transfected HL-60 cells $(55.46 \%)$, CRT-overexpressing HL-60 cells (63.09\%), and CRT siRNA HL-60 cells $(31.46 \%)(\mathrm{P}=0.037)$. As shown in Fig. 4B, compared with the control cells $(1.00 \%)$, the CRT-overexpressed group showed decreased CD11b expression $(0.81 \%)$ and the CRT siRNA group showed significantly increased CD11b expression (7.37\%). After DADS treatment for $48 \mathrm{~h}$, the control group, CRT-overexpressed group and the CRT siRNA group all showed increased CD11b expression (8.24, 6.55 and $12.42 \%$, respectively; $\mathrm{P}=0.033$ ). $\mathrm{NBT}$ reduction assays showed decreased NBT reduction activity in the CRT overexpression group and increased NBT reduction in the CRT siRNA group (Fig. 4C). Following treatment with DADS, the NBT reduction abilities in all groups were increased $(\mathrm{P}=0.024)$.

\section{Discussion}

Large numbers of cytokines and drugs have been shown to induce tumor cell differentiation. Among these, the role of allyl sulfides, compounds that are found in garlic, in the prevention and treatment of tumors has attracted attention (29). DADS, the most active anticancer ingredient in garlic, induces differentiation in several tumor types, including HL-60 cells (5). However, the exact mechanism underlying this process remains unclear.

Previous studies have demonstrated that DADS may induce differentiation in leukemia cells $(12,30)$. These studies analyzed and identified differentially expressed proteins during DADS-induced differentiation in HL-60 cells, including CRT. CRT is a multi-functional protein that regulates various cellular functions, such as calcium homeostasis and intracellular adhesion (31). In addition, increased CRT expression levels have been observed in several cancer tissues, including hepatoma, neuroblastoma, mammary gland cancer, bladder cancer and colon cancer (15). These observations imply that high CRT expression levels could be associated with carcinogenesis in these cancers.

Subsequent to treatment with DADS, the morphology of the HL-60 cells used in the present study demonstrated differentiation into granulocyte-like cells. Consistent with a previous study (5), the results of the RT-PCR and western blot analysis in the current study confirmed the significant downregulation of CRT mRNA and proteins in DADS-treated HL-60 cells compared with untreated cells. These data suggest that CRT is closely associated with DADS-induced differentiation in human leukemia HL-60 cells.

To further investigate the role of CRT in DADS-induced cellular effects, CRT expression was inhibited using siRNA and overexpressed CRT by plasmid transfection in HL-60 cells. MTT assays showed that the downregulation of CRT resulted in the inhibited proliferation of HL-60 cells, while CRT overexpression increased proliferation. After treatment with DADS, cellular proliferation in all cell groups was decreased compared with the control. This indicates that CRT is involved in cell proliferation in DADS-induced HL-60 cells. Transwell invasion assays showed that CRT overexpression can increase cellular invasion ability and that CRT downregulation can decrease invasion ability in HL-60 cells. Following treatment with DADS, the number of invading HL-60 cells in all groups was reduced compared with untreated groups. These results indicate that CRT is involved in cell invasion in DADS-induced HL-60 cells.

CD33 is a transmembrane receptor expressed on cells of myeloid lineage and is usually considered to be myeloid specific (32). CD33 is expressed in $>90 \%$ of AML patients, and is not expressed in the hematopoietic stem cell surface, mature granule cells and other tissues (33). Thus, CD33 is a good target for myeloid leukemia treatment (34). CD11b, also known as cluster of differentiation $11 \mathrm{~b}$ molecule, is expressed on the surface of numerous leukocytes involved in the innate immune system, including monocytes, granulocytes, macrophages and natural killer cells (35). CD11b mediates inflammation by regulating leukocyte adhesion and migration and has been implicated in several immune processes, including phagocytosis, cell-mediated cytotoxicity, chemotaxis and cellular activation (36). Therefore, CD33 and CD11b are important indexes to evaluate the differentiation of myeloid leukemia cells. FCM analysis showed that the expression of CD33 in the CRT siRNA group was markedly reduced, while expression was increased in CRT-overexpressed groups. The expression of CD33 was significantly decreased in all cell groups following treatment with DADS. The expression of CD11b was significantly increased in the CRT siRNA group, and increased in the CRT-overexpressed group. The expression of CD11b was significantly increased in all groups following treatment with DADS. These data demonstrate that DADS-induced HL-60 cells are differentiated to mature neutrophil cells. NBT reduction assays showed that NBT reduction was increased in the CRT siRNA group and reduced in the CRT overexpression group. After treatment with DADS, NBT reduction abilities were increased. These results indicate that CRT is involved in cell differentiation in DADS-induced HL-60 cells.

In conclusion, the present study clearly demonstrates the downregulation of CRT during DADS-induced differentiation in HL-60 cells and indicates that CRT is involved in cell proliferation, invasion and differentiation in DADS-induced HL-60 cells. The data first demonstrated that CRT could play an essential role in AML cell proliferation and invasion, and therefore may be an important target for future research of human AML. The exact mechanisms underlying DADS-induced tumor cell differentiation require further investigation.

\section{Acknowledgements}

The present study was sponsored by the National Natural Scientific Foundation of China (grant no. 81400117; Beijing, China), the Hunan Provincial Natural Science Foundation of China (grant no. 2015JJ4043; Changsha, China), China Postdoctoral Science Foundation (grant no. 2014M562115; Beijing, China) and the returned personnel Initial Funding of University of South China (grant no. 2014XQD46; Hengyang, China). 


\section{References}

1. Rubnitz JE and Inaba H: Childhood acute myeloid leukaemia. Br J Haematol 159: 259-276, 2012.

2. Iland HJ, Bradstock K, Supple SG, Catalano A, Collins M, Hertzberg M, Browett P, Grigg A, Firkin F, Hugman A, et al; Australasian Leukaemia and Lymphoma Group: All-trans-retinoic acid, idarubicin, and IV arsenic trioxide as initial therapy in acute promyelocytic leukemia (APML4). Blood 120: 1570-1580, 2012

3. DiNardo CD and Cortes JE: New treatment for acute myelogenous leukemia. Expert Opin Pharmacother 16: 95-106, 2015.

4. Arunkumar R, Sharmila G, Elumalai P, Senthilkumar K, Banudevi S, Gunadharini DN, Benson CS, Daisy P and Arunakaran J: Effect of diallyl disulfide on insulin-like growth factor signaling molecules involved in cell survival and proliferation of human prostate cancer cells in vitro and in silico approach through docking analysis. Phytomedicine 19 912-923, 2012

5. Yi L and Su Qi: Molecular mechanisms for the anti-cancer effects of diallyl disulfide. Food Chem Toxicol 57: 362-370, 2013

6. Altonsy MO, Habib TN and Andrews SC: Diallyl disulfide-induced apoptosis in a breast-cancer cell line (MCF-7) may be caused by inhibition of histone deacetylation. Nutr Cancer 64: 1251-1260, 2012.

7. Zhou Y, Su J, Shi L, Liao Q and Su Q: DADS downregulates the Rac1-ROCK1/PAK1-LIMK1-ADF/cofilin signaling pathway, inhibiting cell migration and invasion. Oncol Rep 29: 605-612, 2013.

8. Tan H, Ling H, He J, Yi L, Zhou J, Lin M and Su Q: Inhibition of ERK and activation of $\mathrm{p} 38$ are involved in diallyl disulfide induced apoptosis of leukemia HL-60 cells. Arch Pharm Res 31 786-793, 2008

9. Yi L, Ji XX, Tan H, Lin M, Tang Y, Wen L, Ma YH and Su Q: Role of Ras-related $\mathrm{C} 3$ botulinum toxin substrate 2 (Rac2), NADPH oxidase and reactive oxygen species in diallyl disulphide-induced apoptosis of human leukaemia HL-60 cells. Clin Exp Pharmacol Physiol 37: 1147-1153, 2010.

10. Yi L, Ji XX, Tan H, Feng MY, Tang Y, Wen L and Su Q: Involvement of Mcl1 in diallyl disulfide-induced $\mathrm{G} 2 / \mathrm{M}$ cell cycle arrest in HL-60 cells. Oncol Rep 27: 1911-1917, 2012.

11. Wu MH, Huang WG, Tan H, He J and Su Q: Induction of differentiation by diallyl disulfide through inhibition of JAK1/STAT3 in human leukemia HL-60 cells. Zhong Guo Yao Li Xue Tong Bao 21: 580-583, 2005 (In Chinese).

12. Zhao J, Huang WG, He J, Tan H, Liao QJ and Su Q: Diallyl disulfide suppresses growth of HL-60 cell through increasing histone acetylation and $\mathrm{p} 21 \mathrm{WAF} 1$ expression in vivo and in vitro. Acta Pharmacol Sin 27: 1459-1466, 2006.

13. He J, Su Q, Huang WG, Xie HL, Liang SP, Song Y, Xie JY, Zhou XT, Tan H, Zhao J and Wu MH: Proteomic initial analysis of differentiation of human myeloid leukemia cells induced by diallyl disulfide. FEBS J 272 (Suppl 1): S440, 2005.

14. Wang WA, Groenendyk J and Michalak M: Calreticulin signaling in health and disease. Int J Biochem Cell Biol 44 $842-846,2012$

15. Zamanian M, Veerakumarasivam A, Abdullah S and Rosli R: Calreticulin and Cancer. Pathol Oncol Res 19: 149-154, 2013.

16. Liu R, Gong J, Chen J, Li Q, Song C, Zhang J, Li Y, Liu Z, Dong Y, Chen L and Jin B: Calreticulin as a potential diagnostic biomarker for lung cancer. Cancer Immunol Immunother 61 $855-864,2012$

17. Kageyama S, Isono T, Matsuda S, Ushio Y, Satomura S, Terai A Arai Y, Kawakita M, Okada Y and Yoshiki T: Urinary calreticulin in the diagnosis of bladder urothelial carcinoma. Int J Urol 16: 481-486, 2009
18. Chen CN, Chang CC, Su TE, Hsu WM, Jeng YM, Ho MC, Hsieh FJ, Lee PH, Kuo ML, Lee H and Chang KJ: Identification of calreticulin as a prognosis marker and angiogenic regulator in human gastric cancer. Ann Surg Oncol 16: 524-533, 2009.

19. Hsu WM, Hsieh FJ, Jeng YM, Kuo ML, Chen CN, Lai DM, Hsieh LJ, Wang BT, Tsao PN, Lee H, et al: Calreticulin expression in neuroblastoma-a novel independent prognostic factor. Ann Oncol 16: 314-321, 2005.

20. Alfonso P, Núñez A, Madoz-Gurpide J, Lombardia L, Sánchez L and Casal JI: Proteomic expression analysis of colorectal cancer by two-dimensional differential gel electrophoresis. Proteomics 5: 2602-2611, 2005.

21. Chen CN, Su TE, Lu YC and Lee H: Calreticulin regulates cell proliferation and migration in gastric cancer cell line AGS FASEB J 21: A1318, 2007.

22. Kabbage M, Trimeche M, Bergaoui S, Hammann P, Kuhn L, Hamrita B, ben Nasr H, Chaieb A, Chouchane L and Chahed K: Calreticulin expression in infiltrating ductal breast carcinomas: Relationships with disease progression and humoral immune responses. Tumour Biol 34: 1177-1188, 2013.

23. Park S, Huh HJ, Mun YC, Seong CM, Chung WS, Chung HS and Huh J: Calreticulin mRNA expression and clinicopathological characteristics in acute myeloid leukemia. Cancer Genet 208: 630-635, 2015

24. Kourie HR, Ameye L, Paesmans M and Bron D: Improved Survival of Calreticulin-Mutated Patients Compared With Janus Kinase 2 in Primary Myelofibrosis: A Meta-Analysis. Clin Lymphoma Myeloma Leuk 16: 264-268, 2016.

25. Mans S, Banz Y, Mueller BU and Pabst T: The angiogenesis inhibitor vasostatin is regulated by neutrophil elastase-dependent cleavage of calreticulin in AML patients. Blood 120: 2690-2699, 2012

26. Cao H and Shockey JM: Comparison of TaqMan and SYBR Green qPCR methods for quantitative gene expression in tung tree tissues. J Agric Food Chem 60: 12296-12303, 2012

27. van Meerloo J, Kaspers GJ and Cloos J: Cell sensitivity assays: the MTT assay. Methods Mol Biol 731: 237-245, 2011.

28. Wu MH, Su Q, Cheng AL, Tan $\mathrm{H}$ and Song Y: Experimental study of HL-60 cell differentiation induced by diallyl disulfide. Zhong Guo Yao Li Xue Tong Bao 19: 319-322, 2003 (In Chinese)

29. Ling H, Zhang LY, Su Q, Song Y, Luo ZY, Zhou XT, Zeng X, He J, Tan H and Yuan JP: Erk is involved in the differentiation induced by diallyl disulfide in the human gastric cancer cell line MGC803. Cell Mol Biol Lett 11: 408-423, 2006.

30. He J, Su Q, Huang WG, Xie HL, Liang SP, Song Y, Xie JY, Zhou $\mathrm{XT}$, Tan $\mathrm{H}$, Zhao J and $\mathrm{Wu} \mathrm{MH}$ : Proteomic initial analysis of differentiation of human myeloid leukemia cells induced by diallyl disulfide. FEBS J 272: 440, 2005.

31. Michalak M, Groenendyk J, Szabo E, Gold LI and Opas M: Calreticulin, a multi-process calcium-buffering chaperone of the endoplasmic reticulum. Biochem J 417: 651-666, 2009.

32. Walter RB, Appelbaum FR, Estey EH and Bernstein ID: Acute myeloid leukemia stem cells and CD33-targeted immunotherapy. Blood 119: 6198-6208, 2012.

33. Ayadi L, Abid N, Makni S, Bahri I, Frikha I and SellamiBoudawara T: An unusual tumour of the lung. Pathologica 107: $14-18,2015$

34. Jurcic JG: What happened to anti-CD33 therapy for acute myeloid leukemia? Curr Hematol Malig Rep 7: 65-73, 2012.

35. Arora M, Poe SL, Ray A and Ray P: LPS-induced CD11b+Gr1(int) F4/80+ regulatory myeloid cells suppress allergen-induced airway inflammation. Int Immunopharmacol 11: 827-832, 2011.

36. Heo SK, Noh EK, Yoon DJ, Jo JC, Koh S, Baek JH, Park JH, Min YJ and Kim H: Rosmarinic acid potentiates ATRA-induced macrophage differentiation in acute promyelocytic leukemia NB4 cells. Eur J Pharmacol 747: 36-44, 2015. 